\title{
A critical review of forecasting models to predict manpower demand
}

James M.W. Wong (Doctoral candidate and corresponding author, Department of Building and Real Estate, The Hong Kong Polytechnic University, Hong Kong), Albert P.C. Chan(Professor, Department of Building and Real Estate, The Hong Kong Polytechnic University, Hong Kong) and Y.H. Chiang (Associate Professor, Department of Building and Real Estate, The Hong Kong Polytechnic University, Hong Kong)

\section{ABSTRACT}

Forecasting manpower requirements has been useful for economic planners, policy makers and training providers in order to avoid the imbalance of skills in the labour market. Although reviews of the manpower planning models have been conducted previously, with the accumulated experience and the booming of advanced statistical techniques and computer programs, the study of forecasting practices has undergone considerable changes and achieved maturity during the past decade. This paper assesses the latest employment and manpower demand estimating methods by examining their rationale, strengths and constraints. It aims to identify enhancements for further development of manpower forecasting model for the construction industry and compare the reliability and capacity of different forecasting methodologies. It is concluded that the top-down forecasting approach is the dominant methodology to forecast occupational manpower demand. It precedes other methodologies by its dynamic nature and sensitivity to a variety of factors affecting the level and structure of employment. Given the improvement of the data available, advanced modelling techniques and computer programs, manpower planning is likely to be more accessible with improved accuracy at every level of the society.

Keywords : Employment Forecasting, Forecasting Models, Manpower Planning, Manpower Demand, Construction Industry.

\section{INTRODUCTION}

Analysis of manpower supply and demand has a long history and severed as an important tool in the area of human resources planning. The main purpose of manpower forecasting is to facilitate training, which is a long-term investment in any economy. Agapiou (1996) stresses that appropriate training can only be developed if training needs are carefully identified. If employment forecasts had been available to provide forewarning information of likely shortfalls, employment policy makers and training providers might have been able to adjust the supply of skills and thereby mitigate some damaging effects of shortages (Hillebrandt and Meikle, 1985). The need for nationally coordinated manpower planning is crucial as educational and vocational guidance to deal with the problems of growing unemployment, knowledge obsolescence and changing skill requirements (Heijke, 1993).

Manpower is regarded as an important resource upon which the construction industry depends (CIRC, 2001). Identification of imbalances between the demand for and the supply of specific skills in the construction industry is particularly important since it contains a large number of distinct skill categories. Shortages in any particular category can result in 'bottleneck' in output and reduce productivity, whereas surplus of trained workers can cause serious unemployment or underemployment which represents a squander of national resources (Hillebrandt and Meikle, 1985; Kao and Lee, 1998). In addition, the balanced human resources might minimize any sudden surge in labour wages and hence construction cost (Ball and Wood, 1995). The industry could also improve productivity and quality of works by having a stable supply of well-trained workers (VTC, 2001). Manpower forecasting is, therefore, needed to facilitate the construction programmes and to prevent the damage to the economy caused by attempts to undertake construction when and where the resources are not available (Briscoe and Wilson, 1993).

On the demand-side, manpower forecast focuses on the expected quantity of jobs to be available and nature of the requirements in the future (Bartholomew et al. 1991). Nickell (1984) notes that industrial employment has proved notoriously difficult to model as it is related to numerous factors such as rapid technological development, consumers patterns, industrial structure, changes in the level of economic activity, government programs and policies etc.. The assessment of labour market therefore has been a critical challenge to researchers, employment policy makers, manpower analysts and educational planners for decades, with the aim to avoid the imbalance between manpower demand and supply for skills, whether appearing as structural unemployment or skill shortages impeding economic development.

Construction business is highly competitive due to the current economic environment. The viability of business and the ability to compete will depend largely on the cost of construction and the quality of service performed by well-trained staff. Various training institutions such as universities, private-sector firms, employer organisations, trade unions and other training providers, all have a concern with manpower forecast. The forecast information needs to be sufficiently detailed to show expected demand and supply for each occupation in the construction industry.

International interest and debate in the subject dates back to after World War II in Western nations. Ahamad and Blaug (1973) advocate that the interest in manpower forecasting in the past was derived from three different sources: those interested in linking educational expansion to what were called 'manpower requirements' of a growing economy; those realized that targetsetting for GNP eventually entailed a translation of these targets into individual components; and, those concerned with 
vocational counselling and placement services who felt that manpower forecasting could provide a rational basis for their activities. All these strands involve different considerations, but the common belief is that shortages and surpluses of manpower have to be controlled and minimized in all economies (Prasirtsuk, 1993).

The interest was perhaps at its peak in the 1960s, with the establishment of the well-known Mediterranean Regional Project (MRP) by OECD as delineated in detail by Parnes (1962). However, criticisms have come from Ahamad and Blaug (1973), Colclough (1990) and Psacharopoulos (1991) on its estimating methodology and plausible assumptions. In spite of the difficulties and criticisms, the forecasting activities yet continue in both developing and developed countries in the 1990s, but in a less mechanistic and indicative fashion for general aids to policy makers on labour market trends (Briscoe and Wilson, 1993). It tends to confine to a sectoral or regional level, where they are more apt to utilize data information and by adopting more sophisticated methods.

The work in the $20^{\text {th }}$ and $21^{\text {st }}$ century is notable for the rapid changes taking place in sectors of business and industry. Many countries have recognized the importance of manpower forecasting and applied various forecasting methodologies to determine the future training needs. The ability to adapt rapidly to meet new requirements is vital if the country or industry is to find the right number of workers with the right skills. However the literature of manpower forecasting and planning methodologies is quite extensive and fairly incongruent. Despite the fact that historical reviews of the manpower planning models have been conducted since the 70s (e.g. Bryant et al., 1973; Smith and Bartholomew, 1988; Debeauvais and Psacharopoulos, 1985; Campbell, 1997), further reviews related to latest manpower forecasting techniques, especially those that can be adapted for construction, can rarely be found from the literature since then. With the accumulated experience and the booming of advanced available statistical techniques and computer programs, the study of forecasting practices has undergone considerable changes during the past decade. It is therefore timely to conduct a comprehensive review on the manpower forecasting methodologies.

A number of forecasting approaches have been used to determine occupational labour demand. Some generate longterm projections, whereas others are more appropriate for short-term and regional needs. Forecasting the demand of human resources can also be classified by national, industrial, business firm and individual levels for various purposes. This paper focuses on the national and industrial forecasting methodologies, but not limited to the construction sector. It aims to identify enhancements for further development of manpower forecasting approach for the construction industry.

This paper provides a practical examination and synthesis of the recent forecasting techniques so that future development of manpower demand forecast can be sustained. The paper is divided into four parts. Following the introduction, the next section presents a review of the four prevailing demand forecasting methodologies. The strengths and limitations of the four forecasting methods are assessed in turn. The merits of the four categories of forecasting methodologies are then compared based on some common selection criteria. Recommendations for possible future developments are highlighted at the end of this paper.

\section{MANPOWER DEMAND FORECASTING APPROACHES}

Based on the available literature, the rationale, general characteristics, as well as the pros and cons of each technique will be examined in this section. The major manpower forecasting approaches can be categorized into four clusters, namely: time series projection, 'bottom-up' coefficient approach, 'top-down' forecasting models, and the market signalling approaches.

\section{Time Series Projection}

The basic characteristic of a time series extrapolation on the forecasting manning levels is its restriction of the stochastic information by examining a relationship solely between the past behaviour and time and then extrapolating the trend into the future (Bezdek, 1975; Goh and Teo, 2000). The univariate analysis produces a forecast ranges from the use of a simple deterministic model such as linear extrapolation (naïve model) to complex stochastic model (e.g. Box-Jenkins models) for adaptive forecasting (Pindyck and Rubinfeld, 1998). In general, sophisticated methodologies provide better estimates than extrapolation of existing trends or other simple techniques (Rumberger and Levin, 1985).

The Vocational Training Council (VTC) in Hong Kong produces forecasts of manpower requirements for 22 industry sectors using weighted exponential smoothing time series forecasting technique since 1970s. Briefly, in this trend method, the survey data are weighted. The weights used form a geometric series with heavier weights given to the more recent data, i.e., the forecast will be more dependent on the recent data. In addition, the weighted exponential smoothing technique is applied in order to smooth out the random fluctuations in past data so as to reveal the trends (HKTC, 1977; see also Suen, 1998). It has a basic assumption that results from $n$ survey are available,

$$
\overline{\mathrm{D}}_{\mathrm{n}}=\frac{\mathrm{D}_{\mathrm{n}}+\mathrm{D}_{\mathrm{n}-1}(1-A)+\mathrm{D}_{\mathrm{n}-2}(1-A)^{2}+\ldots \ldots}{\sum_{m=0}^{n-1}(1-A)^{m}}
$$

for $n>1$ for all $D$

where $D_{n}$ is the manpower demand at the time of survey; $0 \leq A \leq 1.0$. The larger the value $\mathrm{A}$, the more heavily will the recent data be weighted. The A value could be adjusted to give optimum curve fitting such that either the absolute error or the mean square error of the curve is minimum.

The ratio of the weight moving average

$$
\mathrm{R}_{\mathrm{n}}=\frac{\overline{\mathrm{D}}_{\mathrm{n}}}{\overline{\mathrm{D}}_{\mathrm{n}-1}}
$$


is then similarly operated on as for the basic survey data to give the weighted ratio such that:

$$
\overline{\mathrm{R}}_{\mathrm{n}}=\frac{\mathrm{R}_{\mathrm{n}}+R_{\mathrm{n}-1}(1-A)+R_{\mathrm{n}-2}(1-A)^{2}+\ldots \ldots}{\sum_{m=0}^{n-2}(1-A)^{m}}
$$

for $n>2$ for all $\mathrm{R}$

The forecast value for the first period immediately following the most recent survey, i.e. $D_{n+1}^{\prime}$, is then given by

$\mathrm{D}_{\mathrm{n}+1}^{\prime}=\overline{\mathrm{R}}_{\mathrm{n}} \overline{\mathrm{D}}_{\mathrm{n}}$

Forecast values for later periods, i.e. $D_{n+2,}^{\prime} D_{n+3,}^{\prime} D_{n+4}^{\prime}$ etc can then be found by repeating the above procedures. Time series projection for forecasting manpower requirements was also employed by the Education and Manpower Bureau of the Hong Kong SAR, the Central Office for Education in Finland, the Department for Education and Employment in the UK, and the Government of Poland (Tessaring, 2003).

Univariate time series analysis is fairly reliable, relatively simple and inexpensive (Bartholomew et al. 1991). It also helps discourage introduction of personal bias into the forecasting process. Forecaster could focus on considering the underlying trend, cyclic, and seasonal elements, and takes into account the particular repetitive or continuing patterns exhibited by past manpower-use data (Bryant et al., 1973). However, it should be highlighted that time series models are more suitable for producing only short-term forecasts (i.e. one year ahead) because of its limited structure of the forecasting approach. Another limitation is that they do not give insight into the factors causing the changes in manpower requirements and occupational structure. Evaluations of forecasts hence are impeded so as to learn mistakes in the past. Weaknesses are also on the assumptions that the future will be a continuation of the past. Extrapolation produces large forecast errors if discontinuities occur within the projected time period. It is also disadvantaged by the lack of explanatory capabilities, thus not suitable for applications where explanation of reasoning is critical (Goh and Teo, 2000). Experts' adjustments and verifications are helpful to provide more reasonable forecasting results for policy makers in training institutions and Government bureaux.

\section{'Bottom-up' Coefficient Approach}

The recent developed labour demand forecasting model by Chan et al. (2002) is a representative of the 'bottom-up' coefficient approach. The model adopted labour multiplier approach which was based on the premise that, in each project type, the projects will demand the same level of labour requirement per unit of project expenditure and follow a standard demand pattern. Based on information collected from site returns for daily labour deployment and the project expenditure on past projects, the labour number for each trade in the form of man-day per $\$ M$ (labour multiplier) covering various markets including public works, railway works, and other public utilities were derived as shown in equation [3]. The estimated labour demand by occupation can then be projected by multiplying the multipliers and estimated project expenditure as illustrated in equation [4]. Aggregating the occupational manpower demand deriving from all future projects provide the prospect of the overall industrial labour market requirements.

$\mathrm{L}_{\mathrm{sx}}^{\mathrm{J}}=\frac{\mathrm{D}_{\mathrm{sx}}^{\mathrm{J}}}{\mathrm{E}_{\mathrm{X}}^{\mathrm{J}}}$

$\mathrm{L}_{\mathrm{S}}^{\mathrm{D}}=\sum_{\mathrm{x}} \cdot \mathrm{E}_{\mathrm{x}(\text { est. })}$

where,

$\mathrm{L}_{\mathrm{sx}}^{\mathrm{J}} \quad=$ labour multiplier of trade $\mathrm{s}$ at stage $\mathrm{x}$ of the project type j;

$\mathrm{L}_{\mathrm{S}}^{\mathrm{D}} \quad=$ total labour demand of trade $\mathrm{s}$ for a particular construction project;

$\mathrm{D}_{\mathrm{sx}}^{\mathrm{J}} \quad=$ labour deployment (man-days) of trade $\mathrm{s}$ at stage $\mathrm{x}$ of the project type j;

$\mathrm{E}_{\mathrm{X}}^{\mathrm{J}} \quad=$ project expenditure $(\mathrm{HK} \$ \mathrm{M})$ at stage $\mathrm{x}$ of the project type j.

$\mathrm{E}_{\mathrm{x}(\text { est. })}=$ estimated project expenditure at stage $\mathrm{x}$.

This concept complies with Agapiou et al. (1995) that the labour demand for a construction project is strongly related to the labour productivity, type of project and the volume of work within a particular market sector. Likewise, Rosenfeld and Warszawski (1993), Proverbs et al. (1999) and CWDFC (2002) applied this multiplier approach respectively for the construction industry of Israel, the United Kingdom and Alberta. Smith et al. (2000) estimate the health professional demand by multiplying future utilization rate for different provider settings by projected population in Shelby County, Tennessee. McClean and Reid (1993) also consider the nursing hours per patient (NHPP) ratio as a tool for nurse demand forecasting for the National Health Service (NHS) sector in the United Kingdom.

This forecasting method is designed to establish fixed coefficients for different categories of building, housing and civil engineering works. The categorization will allow different multipliers to reflect the effect of the different technologies used for various project types, and thus different labour productivity in order to make more accurate estimation. The reliability of the forecasting model developed by Chan et al. for the labour demand estimation at project level has been proved by pair comparison approach i.e. compares the actual figures with predicted results.

Although the model can be updated to take account of any changes in technology and labour mix will be reflected by new sets of labour multipliers generated, it requires considerable effort and expense to regularly update the database. It is also 
considered that time lag would be a severe constraint to the fixed coefficient model for the changes on various impacts such as technology, competition, legislation, etc. Therefore, updated coefficients are critical for providing accurate forecasts. Another drawback in the use of this kind of forecasting methodologies is that it depends heavily on the past data and the basic assumption on the sole relationship between the independent variables and the manpower demand. In addition, it is demanding to collect the past employment records and the details of the future project estimates especially on the private sector and the maintenance sector for the industry-based forecast.

\section{'Top-down' Forecasting Model}

Amongst the variety of methodologies used to derive manpower forecasts, top-down forecasting approach is the dominant methodology of tackling the future manpower demand (Hopkins, 2002). It has been adopted by various institutes in both developed and developing countries, including United States of American, United Kingdom, Germany, Netherlands, Italy, Czech, France, Sri Lanka, etc.

The rationale of this method is linking the manpower requirements to the output of the industry and to the developments in the rest of the economy, i.e. it is assumed that the growth of a certain industry will lead to proportional growths of the demand for each occupation within the industry (Willems, 1998; Uwakweh and Maloney, 1991). A natural starting-point of applying 'top-down' approach in the field of manpower forecasting is the methodology used in the OECD's Mediterranean Regional Project (MRP) (see Parnes, 1962). Debeauvais and Psacharopoulos (1985) summarize the MRP forecasting process, so-called 'manpower requirements approach', into four distinctive steps in assessing the required manpower demand by occupational level:

i. Estimating the future level of output $(X)$ between base and target year.

ii. Estimating the structural transformation of the economy by economic sector $(\mathrm{Xi} / \mathrm{X})$, between base and target year.

iii. Estimating labour productivity by economic sector for the target year to derive its inverse ( $\mathrm{Li} / \mathrm{Xi})$, and its change between the base and target year.

iv. Estimating the occupational structure of the labour force within economic sector (Lij/Li) for the target year;

where,
$X=$ output
$\mathrm{L}=$ labour force
$\mathrm{i}=$ economic sector
$\mathrm{j}=$ occupation

The manpower demand function according to this approach amounts to:

$$
L_{i j}=f\left(X, \frac{X_{i}}{X}, \frac{L_{i}}{X_{i}}, \frac{L_{i j}}{L_{i}}\right)
$$

The first three steps in generating the manpower demand forecast are part of general economic planning. It should be noticed that failures in precisely predicting the growth rate and future changes will adversely affect the accuracy of any resulting manpower forecasts. Irrespective of their analytical basis, top-down models have tended to use quantitative techniques related either to the input-output methodology or to econometric techniques (Infante and Garcia, 1990). Given an estimate on the level of output in various economic sectors, the input-output methodology determines the volume of employment by occupation, education and sex in the form of matrix. Technological change and investment can generate significant alterations in the input-output coefficients and consequently in the demand for manpower. Rickman (2001) illustrated utilizing Bayesian estimation technique to incorporate regional input-output information into the industry employment block of the Oklahoma's econometric model.

The second group of techniques concerns the estimation of models through econometric and/or simulation procedures. The procedures contain formulating a set of equations describing the complex interrelationships of the different economic sectors and a number of corresponding variables (Campbell, 1997). It employs statistical and mathematical methods on the analysis of economic observations, with a purpose of giving empirical content to verify or refute concurrent economic theories (Maddala, 2001). For instance, the Institute of Employment Research (IAB) exploited macroeconomics models to give several scenarios of the future 'labour landscape' (Fuchs and Tessaring, 1994). The scenario results generated from a multi-equation simulation model comprising demographic trends, international economic development, the rate of technical progress, price and wage-price mechanism and the assumed economic policy (Willems, 1996).

To derive occupational demand in the last step, time-series extrapolation, consultation with experts and using sectoral labour-productivity factor are the most common methods. Examples of using both occupational trends and qualitative judgement include the IAB in Germany and the Institute for Employment Research (IER) in United Kingdom (Eijs, 1994). The Research Centre for Education and the Labour Market $(\mathrm{ROA})$ in Netherlands uses explanatory models instead of extrapolation to forecast the occupational structure. Technology variable CEI (Capital to Employment Index) and capacity utilization variable were incorporated to represent sectorspecific capital to labour ratio and business-cycle effects (Dekker et al, 1994). More recently, the models used have been more sophisticated, allowing for changing coefficients and responses instead of fixed to economic variables. Such model offers reliable forecasts and the increase in computer sophistication in the past two decades have even provided an unprecedented capability for long range forecasting.

The forecasting methodology currently adopted by Bureau of Labor Statistics (BLS) of the US Government is a typical example of using top-down forecasting approach. The Bureau has been making long-term (10 years ahead) employment 
projections for the United States for 35 years (BLS, 2003). Projecting employment in industry and occupation detail requires an integrated projection of the total economy and its various sectors. It first develops projections of the gross domestic product (GDP) and the major categories of demand and income using a macroeconometric model. This model has approximately 340 behavioural equations which represent the key relationships influencing the growth and composition of the U.S. economy. In order to estimate the intermediate flows of goods and services in the economy required to produce the GPD, 180 sectoral output projections are acquired by means of input-output model and making assumptions and judgements into the macroeconometric model.

Consequently the industry employment is projected in both numbers of jobs and hours by the BLS models. The demand for hours is projected using an estimated equation derived from the first order conditions of a constant elasticity of substitution production function modified to include a time variable. This equation relates an industry's labour demand to its output, its wage rate relative to its output price, and a time trend. Annual average hours per job are then estimated as a function of time and the unemployment rate. The projection of average hours is then used to convert the projection of wage and salary hours into jobs. The results together with industry output provide a measure of labour productivity. Implied rates of change in productivity are examined closely for consistency with historical trends.

The next step of the BLS projections procedures is to develop the occupational employment projections. It is based on an industry-occupation matrix showing the distribution of employment for over 250 industries and 500 detailed occupations. Occupational staffing patterns are derived from the coefficient terms in the matrix. The future change in occupational requirements is jointly determined by identifying individual occupational trends which can be examined on technological change, wage level, etc., and by making judgements on how the pattern will change in the future. Recent evaluations had been made for the reliability of the 1988-2000 employment forecasts. The conclusion reflects that the performance of the forecasts was satisfactory. It states as:

The BLS occupational employment projections were reasonably accurate, correctly capturing most general occupational trends. As with previous evaluations, however, the inaccuracies that surfaced reflected a conservative tilt to the projections. The primary source of error was the projection of changes in the utilization of occupations by industry, or staffing patterns, rather than the projections of industry employment themselves.

(Alpert and Auyer, 2003)

In the United Kingdom, Briscoe and Wilson (1991) adopted cointegration, a relatively new econometrics technique to establish a long-run equilibrium relationship between labour demand and inter alia output and real wages for the engineering sector.
Following the modelling methodology of Hendry (1985), a general dynamic specification was derived with lags on the significant variables. Ball and Wood (1995) also attempted to model the effect of the changes in construction output, disaggregated output, use cost of capital and real construction wages on employment in the industry using the same econometrical modelling technique. A similar model with additional interest rate variable was derived by Briscoe and Wilson (1993) for the construction industry in the UK as outlined in Figure 1. This model is further implemented for forecasting the structure of employment in the UK by Institute for Employment Research (IER) (Wilson, 1994). 


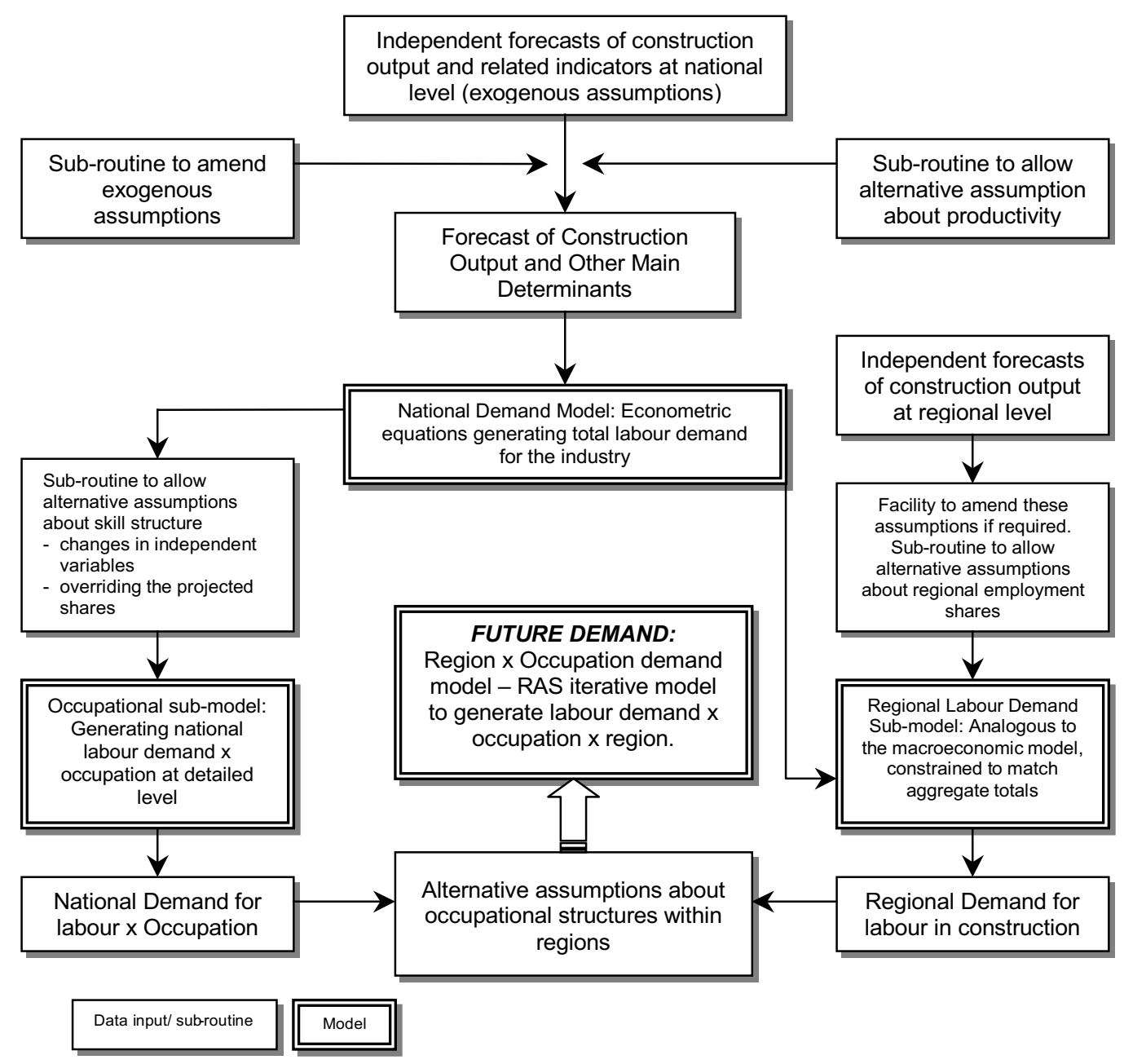

Sources: Briscoe and Wilson (1993)

Figure 1: Scheme outline of a manpower demand forecasting model for the UK construction industry

Briscoe and Wilson demonstrate that there could be an option within the forecasting model to change the values of those key indicators which influence the level of aggregate construction output. The effects are based on simulation analysis using the full macroeconomic model. It is also possible for the national employment function to be overridden by adjusting the total level of employment ceteri paribus and so producing different rates of productivity change in response to technological changes or other factors. The results are sensitive to the assumptions adopted as well as the parameters of the various econometric equations.

The share of each occupation in the national employment total is derived from a separate set of equations which make the respective occupational shares a function of trend, output cycle and various work mix variables. A constraint is applied to ensure that all occupational shares sum to unity. In the Briscoe and Wilson's study, the initial forecast values for the mix variables are based on log linear trend extrapolations. The national employment forecasts are also broken down into regional forecasts using significant explanatory variables in the regional equations. The regional forecasts yield total numbers in employment and these totals are also constrained to sum to the national total.
Once national projections of occupational shares and forecasts of regional employment have been produced, they could be combined to obtain region by occupation estimates. The method adopted by Briscoe and Wilson is a mathematical iterative technique (RAS method), which works mechanistically. The RAS procedures ensures occupational totals and regional employment totals are consistent with the sum of the cells of the region by occupation employment matrix. Diagnostic tests, such as Lagrange Multiplier test for autocorrelation, Engles ARCH test for autocorrelated squared residuals, test for heteroscedasticity, Chow test for structural breaks in regression, were conducted to confirm the efficiency of the model specifications which have been estimated to explain the employment changes.

Top-down forecasting technique is capable to project long-terms (periods of 10 years) quantitative skilled manpower needs (Campbell, 1997). This technique is readily comprehensible on utilizing statistics and has remained popular with economists, workforce planners and policy makers because of its structured modelling basis and acceptable forecasting performance. Econometric modeling precedes other methodologies by its dynamic nature and sensitivity to a variety of factors affecting the level and structure of employment, taking into account 
indirect and local inter-sectoral effects. It can adequately deal with interaction between different labour market segments and substitution processes between occupational groups (Richter, 1986; Cörvers, 2003).

Previous evaluation works of the top-down approach (e.g. Hughes, 1991; Amjad et al., 1990; Hinchliffe, 1993) concluded that the occupation is problematic as it lacks allowance for changes in business environment, job turnover, occupational mobility, etc. It might be possible to produce superior equations by introducing a wider range of work mix indicators and using several work mix or labour mobility determinants to cope with the difficulty. Another shortcoming is that the reliability of the top-down method depends essentially on the accuracy of the plausible assumptions especially in the behavioural context of social science. It is difficult for models which are based on projections of productivity, interest rates and overall output to predict manpower needs. This is because of the obscurity in forecasting economic activity, technological and commercial change. The sensitivity of the forecast to various determinants, however, can be assessed by developing a range of scenarios rather than a 'fixed point' forecast. In addition, considerable care is required on the issue of multicollinearity as many totally unrelated variables might exhibit high spurious correlation, in order to prevent drawing misleading inferences (Briscoe and Wilson, 1993). One of the solutions is to identify which are the key exogenous variables and which need to be treated as simultaneously determined.

\section{Market Signalling Approaches}

Rather than rely exclusively on sophisticated long-term forecasts, together with their shortcomings and limitations, workforce planners increasingly bring labour market signalling (LMS) approaches into play. Psacharopoulos (1991) is one of the early academicians who refutes the usefulness and the rationale behind the tradition manpower planning practice as the sustained criticism and persist replacing the traditional approach by LMS. They are based on the 'market signals' to identify job opportunities and skill requirements (Campbell, 1997). Examples of the signals include movement of relative wages, employer screening practices, enrolment data, employment trends by education and training, unemployment rate by education, skill and occupation, job advertisement, etc. It focuses on education and training qualifications rather than on occupational classifications as the manpower planning concerns, with the aim to estimate pressure on the economic returns on investment in specific skills (Middleton et al., 1993).

The findings from LMS are primarily of value for providing indications of any mismatches between employers' demand for people with differing levels of qualifications and the number who are likely to be available. Planners can monitor labour market conditions, and assess skills strategically important to the economic development by assessing the findings (Hopkins, 2002). This approach is particularly useful when data is inadequate to build a sophisticated time series model or econometric equations. A tracer study of graduates, for instance, helps to assess if the skills supplied by institutions match what the market requires. Subsequently cautious expansion of training enrolments is recommended and associated with rising salaries and high labour-marketabsorption rates (Debeauvais and Psacharopoulos, 1985).

Consensus procedures or key informants survey have been another feasible approach for estimating manpower requirements since 1970s (Bezdek, 1975). It involves the polling of experts or employers closest to the field to obtain their opinions as to what the value of a particular variable is likely to assume in the target year. They are the ones who decide on hiring and are familiar with the demand and supply of the market. Therefore they are the right sources of labour market demand for searching valuable information in a reasonable period of time (Campbell, 1997). Chan and Wong (2004) applied this methodology to assess the employment opportunities for Hong Kong-trained construction-related professions.

The German Employers' Committee on Vocational Training (KWB) also made use of questionnaire surveys for experts in the construction to identify training needs (Bromberger and Fuhs, 2003). The survey findings provide practical recommendations for central government, professional association or training body to possible initial or further training measures. More systematic approach to collect experts' consensus, the Delphi technique, was also employed to assess the future prospects in the labour market areas (e.g. Rajan and Pearson, 1986; Van Wieringen et al., 2002), which was initiated by Milkovich et al. (1972) in the field of manpower planning. The decisive difference between these quantitative methods is that prediction is not only based on calculations but backed up by the strength of experts' knowledge and sources of information.

A combination of two forecasting approaches is not rare in reality. Subsequent to the time series projections by the VTC in Hong Kong described previously, the forecasts were adjusted by training boards based on employers' short-term forecast market trends, technological development and future expectation. The replacement demand factors including normal retirement, age of existing workforce, mobility of workers inside and outside industries are also considered. In Taiwan, Kao and Lee (1998), on one hand applied regression (using rank of the firm as the independent variable) to estimate the labour demand quantitatively for the manufacturing industry. On the other hand, they conducted an enterprise survey to acquire the future soft skill requirements.

The Human Resource Development Council (HRDC) in Canada adopts labour market signalling and manpower forecasting to provide information about future labour market conditions, known as 'Job Futures' (see www.hrdc-drhc.gc.ca/JobFutures). Based on a set of economic models and forecasting tools as well as consultation with private and public sector experts, it provides comprehensive information for individuals and advisors involved in the education and career planning process. The Institute for the Development of Workers' Vocational Training (ISFOL) in Italy also utilizes employer survey and econometric models in order to obtain future skill needs (Gatti, 2003). 
The German Federal Institute for Vocational Training (BiBB) analyze the labour qualification requirements by three main LMS approaches, namely, job advertisement analyses, advertiser follow-on interviews and enterprise survey (Schmidt, 2003). Job advertisement analyses provide empirically verified information about the demand for skilled workers in the labour market and the qualification profiles needed by the employers. Advertiser follow-on interviews are conducted in order to obtain information on reasons for success and failure with filling advertised vacancies. It is conducted at intervals of half a year in order to obtain supplementary information about the vacancy. Enterprise surveys aim at gathering a comprehensive picture of technological and organizational developments within the enterprises and the resulting qualification needs. These results and various labour market research findings were combined and uploaded on to a website (www.frequenz.net) to obtain an overview of the broad range of skill trends from different standpoints. Empirical information on changing requirements for skilled workers provides indications of how to design vocational training and further training schemes in line with the actual needs. This will facilitate future-oriented decisions and actions for vocational education providers, but also for individual participants in the labour market.

For short-term assessment of training needs, LMS is recommended as a tool to help adjust training programme to the changes in market circumstance and, thereby, reduce inefficiencies (Middleton et al., 1993). It can yield current indicators of workforce supply and demand imbalance in labour market and give early warning signals about forthcoming changes. The information is valuable to occupational training planners, who can use it in determining the need for training in a particular occupation in a comparatively easy and inexpensive way (Campbell, 1997). LMS is therefore a useful adjunct to conventional manpower analysis through advocating the need for wage and employment trends not only to guide training decisions but also to evaluate how well labour markets are functioning.

The LMS approaches nevertheless have been heavily criticised. This centred upon the lack of any firm theoretical foundation as well as the practical problems of ensuring that all respondents are adopting common assumptions about the future scenario and that their responses are mutually consistent (Agapiou, 1996). In the case of acquiring knowledge from experts, it is based heavily on opinions, requires costly executive time, and taking a risk that an expert or an employer may not be able to provide accurate forecasts. The qualitative information collected may lack objectivity. It may contain individual bias and be distorted because of personal view, economic uncertainties or business conditions (Bryant et al, 1973). In addition, individual employers are unlikely to make consistent views about the growth and structure of output over the forecasting period, and more seriously, how much weight should be given to the opinion of an individual. Data collected from job advertisement or tracer study should also be constrained to certain sectors of the economy (Campbell, 1997).

\section{A COMPARATIVE EVLUATION}

The forecasting methods are first evaluated by assessing their complexity in terms of input/output requirements. Table 1 reveals the input and output requirements of the four board categories of forecasting approaches in a matrix form. It indicates that the time series projection approach requires minimal data preparation and level of analysis among other methods. In contrast, bottom-up and top-down approaches need vast amount of statistics and records for estimation and the latter may involve sophisticated modelling and analysis for producing long-term forecasts. 


\begin{tabular}{|c|c|c|c|}
\hline & \multicolumn{2}{|c|}{ Input Requirements } & \multirow{2}{*}{ Output } \\
\hline & Data & Tool & \\
\hline Time Series projection & $\begin{array}{l}\text { Historical records ( } 20 \text { years) of } \\
\text { the targeted series }\end{array}$ & $\begin{array}{l}\text { Projection techniques, e.g. } \\
\text { exponential smoothing, Box- } \\
\text { Jenkins modelling, etc. }\end{array}$ & $\begin{array}{l}\text { - Short-term (1-year ahead) } \\
\text { aggregated manpower demand } \\
\text { forecast } \\
\text { - Large forecast error if } \\
\text { discontinuities occur within the } \\
\text { projected time period }\end{array}$ \\
\hline Bottom-up approach & $\begin{array}{l}\text { - Detailed labour returns and costs } \\
\text { of the past projects breakdown } \\
\text { by various market } \\
\text { - Estimated future project costs }\end{array}$ & $\begin{array}{l}\text { Large size of database but } \\
\text { rather simple calculations }\end{array}$ & $\begin{array}{l}\text { - Project-based occupational } \\
\text { manpower demand } \\
\text { - Industry-based occupational } \\
\text { manpower demand by summing all } \\
\text { estimated project-based demand }\end{array}$ \\
\hline Top-down approach & $\begin{array}{l}\text { - Extensive macroeconomic } \\
\text { statistics, e.g. GDP, sectoral } \\
\text { output, unemployment rate, } \\
\text { productivity, interest rate, wage, } \\
\text { etc. } \\
\text { - Future growth of the economy } \\
\text { and relevant determinants }\end{array}$ & $\begin{array}{l}\text { Extrapolations, Advanced } \\
\text { econometrics modelling e.g. } \\
\text { cointegration, vector error } \\
\text { correction modelling, } \\
\text { simulation, sensitivity } \\
\text { analysis, etc. }\end{array}$ & $\begin{array}{l}\text { - Long-term industry-based } \\
\text { aggregated manpower demand } \\
\text { - Occupational and regional } \\
\text { manpower demand can be } \\
\text { obtained by extrapolation, using } \\
\text { labour-productivity factor or } \\
\text { experts' judgement. }\end{array}$ \\
\hline Market Signalling & $\begin{array}{l}\text { - Labour market signals, e.g. } \\
\text { movement of relative wages, } \\
\text { enrolment data, occupational } \\
\text { employment trends and } \\
\text { unemployment rate, job } \\
\text { advertisement, etc. }\end{array}$ & $\begin{array}{l}\text { Relative simple analysis, e.g. } \\
\text { interviews, surveys, tracer } \\
\text { study, etc. }\end{array}$ & $\begin{array}{l}\text { - Existing mismatch signals } \\
\text { (qualitative and quantitative) in the } \\
\text { labour market } \\
\text { - Employers' view on future prospect } \\
\text { of individual occupation }\end{array}$ \\
\hline
\end{tabular}

Table 1: Input/Output requirements of the manpower demand forecasting methodologies

Table 2 summarizes the relative merits of the four categories of manpower demand forecasting techniques based on the evaluations made earlier. The matrix, adapted from Bryant et al. (1973), facilitates the comparison of the advantages of the four categories of forecasting methodologies and permits the rapid evaluation of a method's relative merit with respect to each of the critical selection criteria. The cells of the matrix contain the following code letters: $E$ (Excellent), $G$ (Good), F (Fair), P (Poor), VP (Very Poor). The methodologies were evaluated with respect to the following criteria:

- Forecasting - Estimating of future manpower needs or the effects of some expected manpower problem accurately;

- Scheduling - Time of the satisfaction of anticipated manpower requirements;

- Cost - The costs for delivering manpower demand forecast

- Uncertainty - Assessment of the uncertainty of future events

- Time horizon - Relevant time spans: L - ten years or more; $\mathrm{M}$ - approximately five years; $\mathrm{S}$ - less than one year

- Aggregate - Ability to forecast overall manpower needs

- Individual - Ability to determine the requirements for an individual job or a group of job

- Testing policy changes - Determination of effects of changes in governmental policy upon costs or required manpower levels

- Hierarchy level - The type of personnel the method may be applied to: $U$ (Upper) to management or executive positions; M (Middle) supervisory and technical positions; L (Lower) labour such as production, site workers, clerical.

- Static versus dynamic - Situations at a point in time versus changes and effects over a period of time. 


\begin{tabular}{|c|c|c|c|c|c|c|c|c|c|c|c|c|c|c|c|}
\hline \multirow{2}{*}{ Criteria } & \multirow{2}{*}{$\begin{array}{l}\text { Fore- } \\
\text { casting }\end{array}$} & \multirow{2}{*}{$\begin{array}{l}\text { Sche- } \\
\text { duling }\end{array}$} & \multirow{2}{*}{ Cost } & \multirow{2}{*}{$\begin{array}{l}\text { Uncert- } \\
\text { ainty }\end{array}$} & \multicolumn{3}{|c|}{ Time horizon } & \multirow{2}{*}{$\begin{array}{l}\text { Aggre- } \\
\text { gate }\end{array}$} & \multirow{2}{*}{$\begin{array}{l}\text { Indivi- } \\
\text { dual }\end{array}$} & \multirow{2}{*}{$\begin{array}{l}\text { Test } \\
\text { policy }\end{array}$} & \multicolumn{3}{|c|}{ Hierarchy } & \multirow{2}{*}{ Static } & \multirow{2}{*}{ Dynamic } \\
\hline & & & & & $L$ & M & $S$ & & & & U & $M$ & $L$ & & \\
\hline $\begin{array}{l}\text { Time series } \\
\text { projection }\end{array}$ & $\mathrm{F}$ & G & $E$ & $P$ & $P$ & $\mathrm{~F}$ & G & G & $P$ & VP & $\mathrm{F}$ & G & G & $\mathrm{F}$ & $P$ \\
\hline $\begin{array}{l}\text { Bottom-up } \\
\text { approach }\end{array}$ & G & $\mathrm{F}$ & $P$ & $P$ & $P$ & $\mathrm{~F}$ & G & $\mathrm{F}$ & G & $P$ & G & G & G & G & $P$ \\
\hline $\begin{array}{l}\text { Top-down } \\
\text { approach }\end{array}$ & G & $P$ & $P$ & G & G & G & $\mathrm{F}$ & G & $\mathrm{F}$ & $\mathrm{F}$ & G & G & $\mathrm{F}$ & G & G \\
\hline $\begin{array}{l}\text { Market } \\
\text { Signalling }\end{array}$ & $\mathrm{F}$ & $P$ & $\mathrm{~F}$ & $F$ & $P$ & $\mathrm{~F}$ & $E$ & $P$ & G & $\mathrm{F}$ & G & $\mathrm{F}$ & VP & G & $\mathrm{F}$ \\
\hline
\end{tabular}

Table 2: Evaluation of the manpower demand forecasting methodologies

Although time series projection could provide prompt and economical forecasts, it is not sensitive to the effects of changes in governmental or organizational policy upon required manpower levels and it is more appropriate to be used for shortterm forecasts. Similarly, LMS approaches can detect the occupational mismatch in the labour market in short time span, however they are not a powerful tool to estimate the manpower requirements in the long run. Another constraint of the LMS approaches is that the 'signals' for semi-skilled/unskilled workers are usually not accessible which adversely affects the comprehensiveness of the forecasts.

The forecasts given by top-down and bottom-up approaches are considered to be relatively more reliable, mainly because of their ability to capture the determinants of the manpower requirements and their reliance on econometrical modeling with rigorous verifications. Although bottom-up approach may provide disaggregated manpower forecasts, top-down approach precedes other forecasting methods by its capability of forecasting medium- to long-term projection, the qualifications of assessing the uncertainty of future events and managing dynamic situations in the labour market.

We may conclude that top-down forecasting approach offers the greatest potential for the timely production of reasonable reliable manpower demand forecasts, and for the running of "what if" test scenarios, such as assessing the impacts of major development projects or migration flows on employment and economic output, notwithstanding sophisticated calculations that it might involve. They also have the advantage of being based upon economic theory, which ensures that outputs are consistent with what is known about the fundamental workings of an economy. These explain why top-down approach is the dominant forecasting methodology in the field of manpower forecast. However, the performance of estimating occupational demand can be further improved by other complementary information.

Two additional important remarks must be made here. First, although a number of the forecasting methodologies were developed in recent times, no one approach was guaranteed as the most accurate method in all circumstances. However, intelligent use of statistical methods is still vital to predict the future skill needs. Second, the evaluations provided by this matrix are subjective in nature which may change greatly according to the evaluator's bias. Nevertheless, it can help policy makers or education planners select the most appropriate forecasting method. In spite of this the final decision must not be solely based on a matrix drawn up externally. Decision makers are required to digest the material on the various manpower forecasting methods and reach a decision from the study. Further considerations such as the desired form of forecast, availability of data, ease of operation, and understanding of other users' requirements on the forecasts should be taken into account when selecting an appropriate forecasting technique.

\section{CONCLUSION}

Identifying and forecasting future skill requirements at sectoral level and implementing these requirements in the training system have long been the subject of intensive research efforts and academic discussions. It helps facilitate the development of industry designed to maintain relative balance for the various occupations in the labour market. The pace of technology and changing economic conditions are the driving force to seek for more efficient, innovative or advanced tool for forecasting the prospect of the construction labour market and their implications for the design of vocational training and education to minimize the margins of uncertainty. This paper reviews the prevailing manpower demand estimating methods developed in recent years, ranging from macroeconomic projections to surveys among enterprises. It provides an essential base for further development of manpower forecasting model at sectoral level. The review and the comparative evaluations of the four different types of forecasting methodologies would be valuable for academics, policy-makers of government, public employment services and employment agencies, employers' organizations, unions and education institutions.

Although the "manpower requirements approach" dominates the manpower forecasting practice in the developed countries, macro approaches are relatively deficient in providing detailed insights into specific and new qualification and skill requirements. Forecasting manpower demand must be undertaken on an occupational basis in order to provide a 
practical and meaningful planning of construction skills by matching supply and demand. It is anticipated that qualitative information such as employers' view and expert knowledge and the findings extracted from signalling analysis will be increasingly incorporated, which can be complementary to modelling in the top-down approach relevance to the development of education and training. This principle is equally applicable in other branches of applied science. Having said this, a reasonably accurate but simple model is sufficient for most practical purposes.

With respect to the design of future models, rather than to develop a long-term forecast model, a medium-term forecast (i.e. 5-year plan) is adequate to fulfil the function of manpower estimation. Furthermore, instead of developing a national forecast, the forecast should be confined to sectoral level due to the corresponding characteristics in different economic segments. In addition, to foresee labour demand in the short and medium terms, improved macroeconomic models and the better specification of their inter-linkages with the labour market are essential. Further endeavours to explore this specific area would be valuable.

Future developments in manpower forecasting are inevitably linked to developments in information technology (Bartholomew et al., 1991). We anticipate that, given the improvement of the time-series data available, econometrics modelling techniques and the advanced IT development, improved modelling capability can be realized. Such developments will make manpower planning more accessible and accurate at every level of the society.

\section{REFERENCES}

Agapiou, A., Price, Andrew D.F. and McCaffer, R. (1995) Planning future construction skill requirements: understanding labour resource issues, Construction Management and Economics, 13 (2), 149-161.

Agapiou, A. (1996) Forecasting the Supply of Construction Labour, a doctoral thesis, Loughborough University.

Ahamad, B. and Blaug. M. (eds.) (1973) The practice of manpower forecasting: a collection of case studies, Elsevier, Amsterdam.

Alper, A. and Auyer, J. (2003) Evaluating the BLS 1988-2000 employment projections, Monthly Labor Review, October 2003, pp. 13-37.

Amjad, R., Colclough, C.,Garcia, N., Hopkins, M. Infante, R. and Rogers, G. (1990) Quantitative techniques in employment planning. Geneva: International Labour Office, Switzerland.

Ball, M. and Wood, A. (1995). "How many jobs does construction expenditure generate?". Construction Management Economics, 13(4). pp. 307-318.

Bartholomew, D.J., Forbes, A.F., McClean, S.I. (1991) Statistical Techniques for Manpower Planning, $2^{\text {nd }}$ ed., John Wiley \& Sons, England.
Bezdek, R.H. (1975) The State of the Art-Long Range Economic and Manpower Forecasting, Long Range Planning, 8 (1), pp.31-42.

BLS (2003) at http://stat.bls.gov/opub/hom/homtoc.htm, BLS Handbook of Methods, Bureau of Labor Statistics, The U.S. Department of Labor.

Briscoe, G. and Wilson, R. (1991) Explanations of the demand for labour in the United Kingdom engineering sector, Applied Economics, 23, pp.913-926

Briscoe, G. and Wilson, R. (1993) Employment forecasting in the construction industry, Avebury, Aldershot, United Kingdom.

Bromberger, N. and Fuhs, (2003) Information system for early recognition of sectoral trends - results obtained for the construction industry, Eds. Schmidt, S.L., Schömann, K. and Tessaring, M., Early Identification

Bryant, D.R., Maggard, M.J. and Taylor, R.P. (1973) Manpower planning models and techniques: A descriptive survey, Business Horizon, 16(2), pp.69-78.

Campbell, C.P. (1997) Workforce requirement: the basis for relevant occupational training, Journal of European Industrial Training, 21(8), pp.279-297.

Chan, A.P.C., Anson, M., Chiang, Y.H., Hui, E.C.M., Chan, E.H.W., Tse, R.Y.C., Wong, A.K.D., Mak, S.W.K., Choy, L.H.T., and Wong, J.M.W. (2002) Final Report to the Consultancy Study on the Demand and Supply of Construction Personnel, Unpublished Consultancy Report to the ETWB of the HKSAR Government.

Chan, K.K and Wong, J.M.W. (2004) The changing Hong Kong construction industry: Identification of the training requirements for the Department of Building and Real Estate, unpublished report to the Department, The Hong Kong Polytechnic University.

CIRC (2001) Construct for Excellence, Report of the Construction Industry Review Committee, HKSAR.

Cörvers, F., (2003) Labour market forecasting in the Netherlands: a top-down approach, Eds. Schmidt, S.L., Schömann, K. and Tessaring, M., Early Identification of skill needs in Europe, Cedefop Reference series; 40, Luxemburg.

Colclough, C. (1990) How can the manpower planning debate be resolved? Eds. Amjad, R., Colclough, C.,Garcia, N., Hopkins, M. Infante, R. and Rogers, G. (1990) Quantitative techniques in employment planning. Geneva: International Labour Office, Switzerland.

CWDFC (2002) 2003 Construction Trades Outlook, The Construction Workforce Development Forecasting Committee, the Construction Owners Association of Alberta, Canada.

Debauvais, M. and Psacharopoulos, G. (1985) Forecasting skilled-manpower needs: the experience of eleven countries, edited by Youdi and Hinchliffe, UNESCO, Comedi, Belgium. 
Dekker R., De Grip., A. and Heijke, H. (1994) Indicating the future labour market prospects of occupational groups and types of education in the Netherlands, Ed. Heijke, $\mathrm{H}$.

Forecasting the Labour Market by Occupation and Education, Research Centre for Education and the Labour Market, Kluwer Academic Publishers, Boston, Dordrecht, London.

Eijs, P.V. (1994) Manpower Forecasting in the Western World: The Current State of the Art, Maastricht: Research Centre for Education and the Labour Market, Facaulty of Economics and Business Administration, Rijksiniversiteit Limburg (ROA-RM1994/1E).

EMB (2000b) 1999-based manpower requirement projection by occupational attainment within economic sector, Education and Manpower Bureau of HKSAR.

Fuchs, J. and Tessaring, M.. (1994) Medium and long-term forecasting of employment in Germany, Ed. Heijke, $\mathrm{H}$. Forecasting the Labour Market by Occupation and Education, Research Centre for Education and the Labour Market, Kluwer Academic Publishers, Boston, Dordrecht, London.

Gatti, M. (2003) Network of national surveys on skill needs in Italy, Eds. Schmidt, S.L., Schömann, K. and Tessaring, M., Early Identification of skill needs in Europe, Cedefop Reference series; 40, Luxemburg.

Goh, B.H. and Teo, H.P. (2000) Forecasting construction industry demand, price and productivity in Singapore: the BoxJenkins approach, Construction Management and Economics, 18, pp. 607-618.

Heijke, J.A.M. (1993) Towards a transparent labour market for training decision: in Europe's Human Resources in the 1990's.

Report from the 1993 Cumberland Lodge Conference, pp.60-75.

Hendry, D.F. (1985) Empirical Modelling in Dynamic

Econometrics, Nuffield College, Oxford.

Hillebrandt, P.M. and Meikle, J.L. (1985), Resource planning for construction, Construction Management and Economics, 3(3), pp.249-263

Hinchliffe, K. (1993) Manpower forecasting and rapid labor market analysis: the demand for technical school graduates in Egypt, The Vocational Aspect of Education, 45(3), pp.239-250.

HKTC (1977) Technical Manpower Demand and Supply 19771982, The Hong Kong Training Council, Hong Kong.

Hopkins, M. (2002) Labour market planning revisited, Palgrace MacMillan, New York.

Huges, G. (1991) Manpower Forecasting. A Review of Methods and Practice in Some OECD Countries, Dublin, FÁS/ESRI.

Human Resource Development Council. Job Futures. HRDC, Canada National Career and Education Planning Tool.

Retrieved on 15 July 2004, from http://www.hrdc-drhc.gc.cal JobFutures.

Infante, R. and Garcia, N. (1990) Labour market modelling alternatives, Eds. Amjad, R., Colclough, C.,Garcia, N., Hopkins, M. Infante, R. and Rogers, G. (1990) Quantitative techniques in employment planning. Geneva: International Labour Office, Switzerland.
Kao, C. and Lee, H.T. (1998) Demand for industrial management manpower in Taiwan: Viewpoints of quantity and skill, International Journal of Manpower, 19(8), pp.592-602.

Maddala, K. (2001) Introduction to Econometrics, John Wiley \& Sons Ltd., England.

McClean S., and Reid, N. (1993) Nurse manpower demand: a review of United Kingdom methodologies, Journal of Advanced Nursing, 18, pp.1833-1839.

Middleton, J., Ziderman, A. and Van Adams, A. (1993) Skills for Productivity - Vocational Education and Training in Developing Countries, published for World bank by Oxford University

Press, New York.

Milkovich, G.T., Annoni, A.J. and Mahoney, T.A. (1972) The use of the Delphi procedures in manpower forecasting, Management Science, 19(4), pp.381-388.

Nickell, S. (1984) An Investigation of the Determinants of Manufacturing Employment in the United Kingdom, Review of Economic Studies, 51, pp. 529-557

Parnes, H.S. (1962), Forecasting Educational Needs for Economic and Social Development, OECD, Paris.

Pindyck R.S. and Rubinfeld D.L. (1998) Econometric Models and Economic Forecasts, 4th ed., The McGraw-Hill Companies, Inc., USA.

Prasirtsuk, W. (1993) Education, Training, Manpower Planning and the Persistence of Manpower Shortages: The Case of Thailand's Tourism Industry, a doctoral thesis, The University of British Columbia, Canada.

Psacharopoulos, G. (1991) From manpower planning to labour market analysis, International Labour Review, 130(4), pp.459470.

Proverbs, D.G., Holt, G.D. and Olomolaiye, P.O. (1999) A method for estimating labour requirements and costs for international construction projects at inception, Building and Environment, 34 (1), pp.43-48.

Rajan, A and Pearson, R. (eds) (1986) UK Occupation and Employment Trend to 1990: An employer-based study of the trends and their underlying causes. London: Butterworths for the Institute of Manpower Studies.

Richter, L. (1986) Training Needs Assessment and Monitoring, International Labour Office, Geneva.

Rickman, D.S. (2001) Using input-output information for Bayesian forecasting of industry employment in a regional econometric model, International Regional Science Review, 24(2), pp. 226-244.

Rosenfeld, Y. and Warszawski, A. (1993) Forecasting methodology of national demand for construction labour, Construction Management and Economics, 11(1), pp.18-29.

Rumberger, Russell W. and Levin Henry M. (1985)

Technological Forecasting and Social Change (27), pp.399417. 
Schmidt, S.L., (2003) Early identification of qualification needs in Germany - the GreQueNz research network, Eds. Schmidt, S.L., Schömann, K. and Tessaring, M., Early Identification of skill needs in Europe, Cedefop Reference series; 40, Luxemburg.

Smith, A.R. and Bartholomew, D.J. (1988) Manpower Planning in the United Kingdom: A Historical Review, The Journal of the Operational Research Society, 39(3), pp.235-248.

Smith, K.D., Perez-Johnson, I. and Wooldridge, J. (2000) Uncertainty and forecasting local health professional shortages, Population Research and Policy Review, 19, pp.477-503.

Suen, G.Y.G. (1998) Manpower projection of the information technology sector using neural networks, MSc Thesis, The Hong Kong Polytechnic University, HK.

Tessaring, M. (2003) Identification of future skill requirements. Activities and approaches for European cooperation. Eds. Schmidt, S.L., Schömann, K. and Tessaring, M., Early Identification of skill needs in Europe, Cedefop Reference series; 40, Luxemburg.

Uwakweh, B.O. and Maloney, W.F. (1991) Conceptual Models for Manpower Planning for the Construction Industry in Developing Countries, Construction Management and Economics, 9 (5) pp. 451-465.

Van Wieringen, F., Sellin, B. and Schmidt, G. (2002) Future Education: Learning the future. Scenarios and strategies in Europe, Max Goote Expert Center, Amsterdam University, Amsterdam.

VTC (2001), Manpower Survey Report of the Building \& Civil Engineering Industry, the Vocational Training Council, Hong Kong.

Williems, E. (1996) Willems E. (1996) Manpower Forecasting and Modelling Replacement Demand: An Overview, ROA-W1996/4E, Maastricht.

Williems, E. (1998) Interpreting Gaps in Manpower Forecasting Models, Labour 12 (4), pp.633-641

Wilson, R. (1994) Modelling and forecasting the structure of employment in the United Kingdom, Ed. Heijke, H. Forecasting the Labour Market by Occupation and Education, Research Centre for Education and the Labour Market, Kluwer Academic Publishers, Boston, Dordrecht, London. 
